\title{
Contingência e necessidade na causalidade externa segundo 0ckham: argumentos para revisar a interpretação dominante
}

Carolina J. Fernández

carolinajfernandez@gmail.com

Universidad de Buenos Aires - CONICET, Buenos Aires, Argentina

resumo Neste artigo, pretendemos resumir aquela que, acreditamos, ser, nas últimas três ou quatro décadas, a corrente dominante na interpretação da doutrina de 0ckham acerca da causalidade. Buscaremos desenvolver três estratégias para criticar essa interpretação, cada uma delas pertencendo a um diferente nível: ontologia e linguagem, em um primeiro momento, física, no segundo, e epistemológica no terceiro. 0 resultado de nossa exploração é uma visão menos otimista acerca da doutrina causal de 0ckham.

palavras-chave Guilherme de 0ckham; poderes causais; onipotência divina; nominalismo

Costuma-se dizer que um dos traços característicos do projeto filosóficoteológico de Ockham é ter levado às últimas consequências a identificação aristotélica do conhecimento científico com a conclusão do silogismo demonstrativo. Acrescenta-se que seu principal recurso para tornar possível um conhecimento científico do mundo - o qual, aos olhos de um teólogo cristão como ele, é criado e, portanto, contingente - é extrapolar radicalmente a necessidade, desde as coisas (ou, inclusive, desde os conceitos, tomados isoladamente da proposição), às relações predicativas que ocorrem entre os termos da proposição ou entre as proposições, definidas como signos complexos das próprias coisas ${ }^{1}$. Não obstante, no que concerne a sua posição sobre o conhecimento das relações causais no mundo externo, existe uma interpretação dominante que nega firmemente que a doutrina ockhamista da causalidade possa ser considerada cética e, nesse sentido, rejeita toda comparação com a de David Hume

Recebido em 21 de novembro de 2009. Aceito em 09 de fevereiro de 2010.

Tradução: Angélica Gorga - UFR GS

doispontos, Curitiba, São Carlos, vol. 7, n. 1, p.113-135, abril, 2010 
(MC CORD ADAMS, 1979). Parece-nos que se trata de uma reação desmedida contra uma alusão de Étienne Gilson ou contra os juízos do pioneiro K. Michalsky (GODDU, 1984, p. 26, n.), posto que nenhum especialista autorizado sustentou que Ockham foi pura e simplesmente cético sobre a causalidade. Se ele foi comparado, nesse ponto, com Algazali, não foi mais do que para beneficiar a esse, argumentando que, como Ockham, não deve ser indicado como cético - qualificativo que, diga-se de passagem, vai permanecendo assim sem referentes. Há algum tempo, tem-se questionado que a doutrina ockhamista da onipotência divina tenha consequências céticas quanto à operação das causas segundas, produzindo, em última análise, uma semelhança entre Ockham e Tomás de Aquino (GODDU, 1984, p. 216-219), algo que não surpreende, levando-se em conta que nem mesmo Gabriel Biel é considerado um radical nesse ponto (OBERMAN, 2001). Evidentemente, nos estudos sobre o "ceticismo" causal medieval, tem-se produzido uma evolução semelhante a que se verificou na historiografia do conceito de Nominalismo, que começou abarcando os mais diferentes nomes e períodos, desde o século XII ao século XV, desde Roscelino aos nominales do Renascimento, para logo ser progressivamente restringido (COURTENAY,1992). Mas, acima de tudo, o que se manifesta nessa evolução é a atração que gera, nas correntes analíticas contemporâneas, a ambição da filosofia ockhamista de combinar uma concepção naturalista, universalista e externalista do conhecimento humano com um programa ontológico antirrealista, no sentido medieval do termo. A doutrina da causalidade é entendida como parte integrante e essencialmente não discordante desse programa filosófico.

Neste trabalho, proponho-me explorar possíveis linhas de argumentação para revisar a chamada interpretação dominante, bem representada por ROBERT (2002). A tese central dessa interpretação é que Ockham concebe as relações causais naturais como fundadas em poderes ou virtudes disposicionais independentes de toda construção do intelecto humano e que isso não é incompatível com sua explícita adesão a um programa ontológico antirrealista em matéria de universais, relações e demais predicamentos, exceto substâncias e qualidades. Isso implicaria que Ockham entende a causalidade como internamente contida nos objetos (embora de forma não real, caso contrário seria suscetível das 
mesmas críticas que ele formula contra o realismo por multiplicar as entidades). Essencialmente, essa é a mesma tese que GODDU defende em seu até agora insuperado livro sobre a fisica de Ockham (GODDU, 1984). Segundo esses intérpretes, essa concepção seria essencialmente distinta da humeana, que não admite mais que "relações externas" aos objetos. Segundo essa interpretação dominante, a adesão de Ockham à ideia de "poder" ou virtude causal manifestar-se-ia, antes de tudo, no fato de que ele, na maioria das vezes, formula os enunciados causais gerais na forma da possibilidade e não da realidade. A isso acrescenta-se sua ênfase habitual em que a atuação das causas naturais está sempre sujeita ao cumprimento de condições determinadas e particulares (como a aproximação ou o afastamento requeridos pela natureza do agente e do paciente que intervém nesse fato causal pontual, a remoção de obstáculos que impedem a atuação da causa, a aptidão do paciente, a cooperação de alguma causa parcial concorrente, etc.). A raiz da distinção entre Ockham e Hume residiria em que, enquanto Ockham desenvolveu uma ontologia substancialista-qualitativista -em seu vocabulário, uma ontologia da res absolutae-, Hume desenvolveu uma ontologia do evento. E nem por isso a ontologia do filósofo medieval deixa de admitir poderes ou virtudes causais, desde que não os assemelhe à terceiras entidades que mediam entre as substâncias ou qualidades e suas respectivas ações causais. Pelo contrário, tais poderes seriam essenciais ou naturais às coisas absolutas no mesmo sentido em que as essências ou naturezas das coisas absolutas são suas próprias partes reais (no caso das substâncias compostas, suas matérias e suas formas), e não terceiras entidades adicionais a sua própria união. A aceitação, da parte de Ockham, de que se conhece a causalidade a posteriori e sobre a base do princípio extrínseco de uniformidade da natureza ("Causas da mesma espécie, ceteris paribus, têm efeitos da mesma espécie"), não afetaria essencialmente, segundo a interpretação dominante, esse dispositivo teórico projetado por Ockham para, por um lado, salvaguardar a estabilidade do curso natural, mas por outro, evitar o necessitarismo.

Segundo a interpretação dominante, a teologia de Ockham sempre não só não se opõe, mas confirma esta doutrina: assim como a necessidade causal da natureza é relativa - posto Deus à parte -, porque toda operação causal está condicionada à aproximação da causa e ao cumpri- 


\section{6}

mento das condições que esta requer para atuar, analogamente, a necessidade de que determinados poderes causais pertençam a determinados objetos está condicionada à existência mesma de tais objetos e, em termos gerais, do mundo, que depende do Criador. Mas, uma vez criado, o "mobiliário" do mundo torna-se fixo, não só em relação às suas essências, mas também às suas virtudes causais (entendidas, no sentido explicado, como capacidades de ação vinculadas ou, inclusive, identificadas com essas mesmas essências). De fato, uma vez que Deus criou (pelo menos) um homem dotado de racionalidade, a proposição "O homem é racional" é necessária. (Em outras palavras, a necessidade não reside na proposição tomada isoladamente, mas como consequência de um condicional no qual se cumpre a condição de existência). Da mesma forma, uma vez que Deus criou o fogo dotado da capacidade de queimar, a proposição "Todo o fogo pode queimar" será igualmente necessária e Deus não poderá torná-la falsa, ainda que a Bíblia revele que pelo menos em alguns casos Deus substituiu o fogo na ação de queimar ou suspendeu sua ação. Então, ao formular as relações causais em termos de possibilidade, Ockham teria conseguido proteger os poderes causais das criaturas da possibilidade de que Deus opere, in casu, sem intermediários, como ensina a teologia.

A interpretação dominante tem feito justiça ao fato evidente de que Ockham projetou uma série de dispositivos teóricos para fundamentar o conhecimento humano da ordem causal externa. Mas pensamos que essa interpretação, ainda que tenha indicado as fragilidades desses dispositivos (por exemplo, reconheceu a interdependência, próxima à circularidade, que haveria entre os princípios de semelhança específica e uniformidade causal (GODDU, 1984, p. 93-94) ou que a noção de "poder causal" seria um tipo de último termo ou não analisável), as minimizou. Em todo caso, argumentou que, no interior do sistema de idéias do autor, existem tendências contrapostas, cujas respectivas consequências não foram extraídas por ele mesmo, senão pela posteridade, ainda que se tenda a identificar em Ockham uma vontade predominantemente anticética, naturalista, etc. (GODDU, 1984, p. 18ss. e 210ss). De nossa parte, pensamos que se pode interpretar a doutrina ockhamista da causalidade de forma que resulte mais concordante com o espírito antirrealista (no sentido medieval do termo), antimetafísico e contingentista do autor, um pouco 
diferente do que reflete a interpretação dominante. Consideraremos três perspectivas de análise que podem ser aproximadamente caracterizadas como ontológica, cognoscitiva e teológica e tentaremos apresentar as seguintes teses básicas: 1. Em Ockham, as relações causais não significariam diretamente coisas externas, mas algum tipo de complexo mental que media entre os conceitos relativos e os estados de coisas; 2 . A via de conhecimento das relações causais descrita por Ockham não é análoga à via de conhecimento que ele mesmo descreve para, por exemplo, as relações de semelhança; 3. O programa ontológico de Ockham não parece poder admitir "poderes" ou virtudes causais reais a menos que sejam coisas, mas então seriam, ou bem realmente distintas das coisas absolutas - portanto, separáveis por Deus e, nessa medida, contingentes -, ou bem realmente idênticas às coisas absolutas - mas então não se vê a utilidade de distinguí-las delas, e descarta-se que se distingam por uma distinção formal ou de razão, posto que Ockham rejeita essas distinções.

1. Comecemos por desenvolver o primeiro argumento, relativo ao estatuto ontológico das relações. Para isso, cabe primeiro explicar a rica análise ockhamista da causalidade desde o ponto de vista linguístico. A esse respeito, Ockham faz três contribuições centrais: duplica cada um dos quatro gêneros de causas distinguídos por Aristóteles segundo sua significação real e própria ou nominal e imprópria; interpreta toda a terminología causal da física aristotélica conforme o seu programa de discriminar entre as realidade externas e os signos mentais ou linguísticos e incorpora diversos termos semanticamente associados com a noção de causalidade (ação - paixão, etc.) em sua teoria geral da conotação. Sua discriminação entre um significado real e um significado nominal de cada um dos quatro gêneros aristotélicos de causas - material, formal, etc. deriva de sua interpretação dos predicamentos aristotélicos, exceto a substância primeira e certas espécies de qualidade, como termos que não significam realidades externas absolutas e distintas das próprias substâncias e qualidades. "Causa material", "causa formal”, "causa eficiente”, etc., podem significar, respectivamente, a matéria, a forma, o agente, etc., de uma realidade externa nova (uma nova substância ou qualidade), mas também podem significar uma mera reconfiguração por movimento local de realidades externas preexistentes - e no segundo caso tais termos são 


\section{8}

usados imprópria, ampla ou transitivamente. Assim, ao duplicar os sentidos do termo "causa" nos seus quatro gêneros, Ockham reage contra certa reificação das mudanças feitas por arte e que poderia surgir do comentário de Averróis à Física ${ }^{2}$ e contra a reificação da quantidade, difundida entre vários autores. Ockham considera-se fiel à tradição, na medida em que mantém a distinção entre os quatro tipos de causas de Aristóteles, mas também unifica os quatro sob a definição geral de causa como "aquilo cujo ser segue outra coisa", definição popularizada por Pedro Hispano (OCKHAM, 1985, I, cap. 1, p. 18, lin. 92ss.)

Além disso, ao duplicar os quatros sentidos de causa em reais e nominais, Ockham distingue entre duas suposições do termo "causa". Tomada em suposição pessoal, pro re, "causa" não pode estar senão pelas realidades externas, com suas partes intrínsecas, ou por suas qualidades reais, todas as quais (as substâncias, suas partes e suas qualidades) são, enquanto externas, individuais; somente se tomada em suposição simples, “causa” pode estar por algo universal e tal será algum conceito da alma, apto para supor, por sua vez, aquelas entidades externas. Essa distinção permite-lhe estender seu individualismo ontológico aos princípios hilemórficos. Ele repetirá que somente se tomamos o termo, não pela coisa significada, a qual está primeiramente destinado, mas pelo conceito mental ou o nome da própria coisa, poderemos aceitar que "causa" nos seus quatro gêneros (material, formal, etc.) signifique algo universal e será correto dizer, por exemplo, que existe uma causa material, formal, etc. A matéria, a forma, o agente, etc. são tantos como os compostos que, respectivamente, integram ou produzem. Por isso, falando apenas dos conceitos mentais ou dos nomes comuns "causa material", "causa formal", "causa eficiente", etc., aptos para significar múltiplas matérias, formas, agentes, etc., poder-se-á dizer com verdade que são universais. Se Aristóteles ou Averróis aludem “à” matéria, "à" forma ou "às quatro" causas como princípios da física, diz Ockham, eles devem ser interpretados assim (OCKHAM, 1985, II, cap. 5, $\int 1$, p. 279, lin. 39-48.)

A exploração lingüística da causalidade completa-se com uma interpretação antirrealista de termos como ação e paixão, movimento, troca, etc., pela qual Ockham pretende dar conta da diversidade e objetividade significativa de todos esses nomes, sempre evitando os compromissos do realismo. A chave é a teoria geral dos nomes conotativos que, na sua 
expressão corrente, "significam mais de uma coisa, mas não supõem tudo aquilo que significam". Assim como, por exemplo, "branco" significa duas res - a substância in recto e a brancura que a informa in obliquo -, mas na proposição não supõe ambas, senão precisamente a substância, da mesma maneira, actio não somente significa o agente, senão também conota o paciente, mas supõe precisamente o primeiro, sendo o inverso para o predicamento "paixão" (OCKHAM, 1984a III, c. 2, p. 46, lin. 46-58). Os substantivos abstratos "ação" e "paixão" não significam realidades diversas das significadas pelos verbos e particípios "atua" e "agente", "padece" e "paciente"; o termo "movimento" supõe um e o mesmo fato, conotando algo diferente conforme se o nomeado é o motor ou o movido e tal fato não é senão algo absoluto - uma nova forma substancial ou qualitativa -, cuja causa eficiente, seu paciente receptivo, etc. podem ser conotados (OCKHAM, 1984b III, cap. 28, pp. 333, lin. 4 - p. 334, lin. 16).

Essa análise lingüística da causalidade tem consequências importantes. Ockham, segundo o explicado, reage contra a reificação das mudanças produzidas por arte como uma duplicação espúria, ilegítima, das mudanças naturais. Chama a atenção sobre o estatuto estritamente mental de todas as generalizações de que a ciência física se vale ("causa", "forma", "matéria", "princípio") e, finalmente, manifesta-se contra a postulação de realidades transitórias e respectivas - posição majoritária, em uma época que acusava o impacto do realismo formal escotista. Tudo isto implica outorgar uma incidência nunca antes tão alta ao mental, conceitual, ideal, etc., na explicação filosófica da causalidade. Ockham amplia o número dos casos em que a linguagem causal pode ser explicada por referência a conceitos da alma ou entes linguísticos, em vez de realidades externas. Essa nova incidência do mental na explicação filosófica da causalidade soma-se ao seu profundo horror aos universais externos e a sua ênfase de que propriamente não há outros sujeitos e predicados aptos para entrar nas proposições da ciência senão os universais (ainda que seja em uma "ciência real", cujos termos supõem coisas externas). Tudo isso parece conduzir a uma crise da necessidade causal de re ou in rerum natura e seu desdobramento nas relações de predicação no seio da proposição.

A interpretação dominante costuma enfatizar, no entanto, o fato de que Ockham enquadra a causalidade entre as relações reais e não entre as 
relações de razão (GODDU, 1984, pp. 92-93). Ockham não reduz a causalidade a uma pura ficção da mente, pois afirma que a causalidade, não sendo alguma coisa mais que as coisas reais, pode ser entre verdadeiras coisas reais. Acreditamos que, ao fazer essa observação, não se levou suficientemente em conta o fato de que Ockham concebe as relações em geral - portanto, também a de causalidade - como termos de segunda intenção, o que implica que não suporiam diretamente nada extramental. $\mathrm{Na}$ verdade, B. Beretta, que estudou o tema a fundo, demonstrou que, apesar de algumas hesitações sobre se a relação constitui um termo de primeira ou segunda intenção, nos escritos de Ockham predomina a segunda resposta. Relativos são, propriamente, os nomes (tanto mentais, quanto falados e escritos) e não as coisas, posto que a relação é essencialmente de ordem gramatical: não se dá sem a coordenação de dois nomes, um em caso reto e o outro em caso oblíquo (BERETTA, 1999, pp. 2386). Nesse sentido, os extremos da relação são, propriamente, dois nomes (isto é, signos, conceitos ou vozes) correlativos, e apenas impropriamente aquilo do que tais nomes se verificam ${ }^{3}$. Surge, nesse ponto, o problema de explicar em que sentido Ockham mantém a distinção tradicional entre relações reais e relações de razão, sobretudo quando as distingue em termos de independência ou dependência com respeito a intervenção do intelecto. Por exemplo, ainda que em nenhum caso - dentro do criado uma relação possa constituir uma terceira realidade separada ou inerente às coisas absolutas, algumas relações se dão sem nenhuma operação do intelecto; outras não. As relações causais encontram-se entre as primeiras.

Surge nesse ponto a questão do que é significado pelas relações em geral e pelas chamadas "relações reais" em particular. Trata-se de problema muito discutido na teoria ockhamista da linguagem mental, como se define o vínculo de suposição, semelhança e/ou causalidade do conceito ou signo mental com o significado (RAYMAN, 2005). Além disso, pertencendo à classe dos termos ou conceitos conotativos (por oposição aos absolutos), a relação é suscetível da mesma dificuldade que muitos especialistas têm visto naquele tipo de conceito: se não são elimináveis da linguagem mental (especialmente por conter termos sincategoremáticos, que não correspondem a nada extramental), a relação em geral (portanto, a relação de causalidade) implicará, na alma, um "algo mais", um adicional às coisas absolutas externas. A "passividade" do intelecto, em 
resposta ao mundo externo, que frequentemente se interpreta como uma garantia da objetividade dos conceitos em Ockham, parece ser, assim, questionada, pelo menos no caso dos conceitos relativos, na medida em que são um tipo de conceito conotativo, como no caso dos relativos causais. Tentarei exemplificar o problema com esse tipo de relativo.

Um conceito relativo mental como "causa"4, na medida em que cai sob o predicamento da relação, é definível por meio da definição que podemos chamar nominal e que Ockham chama exprimens quid nominis. Todos os outros conceitos que caem sob outros predicamentos que os de substância ou qualidade são definíveis com a definição que podemos chamar real e que Ockham chama definitio exprimens quid rei (OCKHAM, 1974, I, c. 26, p. 689, lin. 1 - p. 690, lin. 8). O nome "causa" é equivalente a uma oração:

“(...) si quaeras quid significat hoc nomen 'causa', potest dici quod idem quod haec oratio 'aliquid ad cuius esse sequitur aliud' vel 'aliquid potens producere aliud', vel aliquid huiusmodi" OCКНАM, 1974, I, c. 10, p. 37, lin. 49-51

Em outros textos de Ockham, a oração é maior:

“(...) illud quod posito potest aliud poni, circumscripto quocumque alio, et quo non posito non potest aliud poni naturaliter, est causa illius" OCKHAM, 1981, qq. 12-13, p. 276, lin. 19-21.

Trata-se de uma frase complexa, composta de dois membros unidos por uma conjunção, cada um dos quais com sujeito, verbo e sincategoremas. Precisamente, a impossibilidade de eliminar as definições nominais e reduzi-las a termos absolutos consiste em que esses tipos de definições contêm termos sincategoremáticos que não correspondem, ponto por ponto, a nada de realidade extramental, diferentemente dos termos categoremáticos. Esse tipo de termo é, por outro lado, imprescindível para dar conta da constituição de proposições completas e bem formadas, tanto na linguagem como no intelecto. Como se sabe, pois tem sido suficientemente demonstrado pelos especialistas, Ockham pensou primeiro que os termos sincategoremáticos seriam abstrações mentais extraídas da linguagem convencional. Posteriormente, modificou sua posição e sustentou que se tratariam de produções naturais da mente. Para alguns especialistas, a introdução desses termos na linguagem 
mental, no mesmo nível dos signos naturais, implica carregar um compromisso ontológico que é inconsequente com o programa ontológico de Ockham (BERETTA, 1999, 155-176). Seja como for, o que parece certo é que o conceito de causa (e o mesmo vale para seu conceito correlativo, 'efeito') significa diretamente uma composição proposicional que requer, como tal, tanto os signos propriamente significativos, que supõem algo externo, como os signos puramente cosignificativos, que não supõem nada de externo. Nessa medida, podemos pensar que, para Ockham, o conceito de causa é um produto imediato do intelecto e não um reflexo puro da realidade exterior, independentemente do fato de que ele não possa constituir-se na mente se na realidade externa não se derem determinadas condições.

2. Analisemos agora a posição de Ockham sobre o conhecimento da causalidade. Segundo a interpretação dominante, Ockham não chega à posições céticas, mesmo reconhecendo que, para seus próprios critérios epistêmicos, não há conhecimento estritamente científico dessa relação. Para reconsiderar essa questão, é preciso voltar à frequente comparação dos intérpretes entre o tratamento ockhamista das relações de semelhança e causalidade. Acabamos de argumentar que, em Ockham, todas as relações poderiam ser entendidas antes como nomes de construções mentais que como nomes diretos de realidades e nisso consideramos que estariam incluídas tanto as relações de semelhança, como a de causalidade. Tentaremos agora argumentar que, para Ockham, a semelhança e a causalidade não são estritamente equiparáveis quanto à sua via de conhecimento. Em suma, o conhecimento de semelhança não é a conclusão de um silogismo não demonstrativo como ocorre com o conhecimento da causalidade. Buscaremos mostrar que essa diferença acarreta uma consequência relevante não suficientemente levada em conta pela interpretação dominante, a saber: se Ockham tem uma posição "externalista", naturalista, espontaneista - ou como se quiser chamá-la - a respeito do conhecimento da semelhança, ela não é automaticamente transferível a sua maneira de entender o conhecimento da causalidade. É precisamente nesse silogismo não demonstrativo, no próprio coração do sistema de verificação da causalidade, que Ockham introduz um elemento de instabilidade: nosso conhecimento de (pelo menos) alguns enunciados causais 
primários - admite ele - é apenas provável, devido a nossa incapacidade para isolar perfeitamente, já não apenas algumas substâncias de outras (dificuldade que pode salvar-se mediante uma aproximação e afastamento minuciosos, como o tem assinalado a interpretação dominante), mas todas as realidades contingentemente unidas no curso comum da natureza, isto é, as substâncias, das qualidades que, como reconhecem os intérpretes, têm ações próprias. (A inseparabilidade de fato das partes intrínsecas, a matéria e a forma, não seria um problema, porque a matéria é, por definição, inativa, de modo que não se vê a necessidade de separála para verificar se tem atos próprios. A noção de matéria foi amplamente estudada por Ockham em seus diversos escritos físicos.

Vejamos primeiramente como Ockham descreve nosso conhecimento das relações reais de semelhança. Ele afirma que o conceito relativo de semelhança é gerado posteriormente - segundo uma ordem de posterioridade natural - ao conceito específico daquele que, em linguagem tradicional, se denomina o "fundamento" da relação. Por exemplo, vistas duas brancuras (o que não é possível a menos que sejam intuídas em duas coisas brancas), é causado no intelecto o conceito específico de brancura e posteriormente é causado o conceito de semelhança, não sendo muito claro se pelas duas brancuras externas junto com o conceito específico de brancura que estas geraram, como causas imediatas parciais, ou pelo conceito específico de brancura como única causa imediata e as brancuras externas como puras causas mediatas, remotas ou "causas da causa" (OCKHAM, 1980, IV, q. 17, p. 386, lin. 136 e 142-147).

Distinto parece ser o caminho que Ockham descreve para conhecer a relação de causalidade. Convém lembrar que Ockham desenvolve a teoria do conhecimento da causalidade no contexto da teoria da demonstração (WEBERING, 1953, 125-133; GODDU, 1984, 52-111). Há proposições que, sem serem cientificamente demonstráveis em sentido próprio, são indispensáveis para demonstrar inúmeras propriedades que interessam em muito ao discurso científico, trata-se do tipo de propriedade que chamamos correntemente "disposicionais". Para dar um exemplo: que todo calor pode aquecer, não é matéria de demonstração - pois não há de onde extrair o termo médio para a demonstração -; no entanto, que alguma coisa, na medida em que é quente ou é sujeito do calor, pode aquecer, admite demonstração . É necessário, para 
tanto, oferecer um procedimento estável, se não estritamente científico, pelo qual são obtidas essas proposições universais que podem servir de meios em alguma demonstração. Esse procedimento envolve, antes de tudo, os seguintes passos:

“(...) apprehenso per sensum calore, potest intellectus eundem calorem cognoscere, et scire quod illud est calidum, et quod illo approximato alteri calefacit illud aliud quod non esset calidum nisi sibi primum calidum approximaretur. Et ita intellectus evidenter cognoscit hanc propositionem 'hoc calidum calefacit"'. (OCKHAM, 1974, III-II, cap. 10, p. 525, lin. 9-14.)

Se considerarmos que se distinguem aqui: 1. apreensão ou nota intuitiva de uma qualidade; 2 . formação e assentimento a uma proposição de existência e inerência qualidade -substância e 3. comprovação experimental da proposição causal particular (vgr., $x$ é o calor; $y$ é quente; “ $y$, enquanto é quente, aquece"), vemos que o conhecimento da causalidade, como Ockham o descreve, pressupõe, em primeiro lugar, a formação ou apreensão de, e assentimento a, uma proposição (o que Ockham explicitamente negava quando explicava a obtenção do conceito de semelhança $)^{6}$ e, em segundo, a realização de um experimentum de singulari de aproximar e remover, etc. ${ }^{7}$. Isso, a meu ver, implica que Ockham não descreve o conhecimento de uma relação causal entre as coisas externas em termos de uma reação espontânea anti-proposicional da mente à causalidade do mundo externo, termos, como vimos, em que descrevia o conhecimento da relação de semelhança - também, entre coisas externas.

É preciso fazer agora uma digressão sobre a física de Ockham, cujos princípios são a matéria e as formas substanciais e acidentais. A matéria é descrita por ele como uma res com atualidade própria, simples e da mesma razão em todos os seres (OCKHAM, 1984b, I, cap. 9, p. 179, lin. 6-9), e a forma substancial, como res de razão diferente em diversos entes, mas igualmente simples, real e extensa como a matéria OCKHAM, 1984b, cap. 15 , p. 196, lin. 8-14 e p. 197, lin. 44-46), com a qual pode fazer algo uno por si - mas não porque o composto seja uma realidade adicional à pura coincidência local de forma e matéria, mas porque nem uma nem outra, apesar de serem reais e realmente reciprocamente distintas, podem existir na natureza mais que como partes do composto (OCKHAM, 1984b, I, cap. 17, p. 199, lin. 5-14). Finalmente, as formas 
acidentais são entendidas como realidades únicas por si (res per se una), por cuja ocorrência ou destruição pode dizer-se que uma substância se altera, e que diferem das formas substanciais enquanto constituem uma unidade acidental com o composto, sem que tal unidade seja - novamente - algo mais que coincidência dessas duas realidades no mesmo lugar. Ockham chega a diferenciar a unidade do ente natural, a do artefato e a da entidade coletiva exclusivamente em termos de se suas partes se unem, respectivamente, por coincidência em um mesmo lugar, por contiguidade sem intermediários e por disposição com uma ordem devida (OCKHAM, 1984b, I, cap. 19, p. 207, lin. 77 - p. 208, lin. 98.) Mas ainda que "matéria", "forma" e "acidente" sejam termos (os únicos da ontologia aristotélica) que significam realidades externas, Ockham não considera tais realidades apreensíveis em si mesmas com um conhecimento próprio e simples, sensível ou intelectual, mas postuláveis por uma série de argumentos filosóficos que procedem por composição de nossos conceitos próprios e comuns das entidades concretas. Por exemplo: tidos os conceitos de "algo", de "estar privado de", de "estar debaixo de" e compostos todos eles em um único conceito, podemos concluir que há algo verdadeiramente externo à alma, pelo qual esse conceito composto pode supor e isso subjaz a todas as mudanças empíricas. Chamamo-lo matéria primeira. De modo similar, chegamos ao conceito de "forma" (OCKHAM, 1984b, I, cap. 14, p. 194, lin. 1 - p. 195, lin. 19). Que certos acidentes sejam verdadeiramente reais e absolutos, distintos das substâncias, é algo que não se sabe senão por um argumento que diz, aproximadamente, o seguinte: se não podemos explicar que uma realidade externa mude de um contraditório a um outro apenas por seu movimento local, por modificações quantitativas, de lugar ou de posição relativa à outras, devemos conceber que ali houve aquisição ou perda de um acidente real. Mas, na verdade, existem acidentes tais que, quando adquiridos, estão de forma nova, segundo todas as suas partes, em cada uma das partes da substância (OCKHAM, 1985, II, cap. 1, \ 4, p. 217, lin. 50ss). Isso não acontece com as formas dos artefatos, uma vez que sua geração pode ser explicada por puras mudanças nas categorias nominais como quantidade, lugar, posição, etc. Exemplos frequentes do mesmo são a rarefação e a condensação do ar ou a geração de entidades coletivas como povo, reino e exército. 
Explicar a variedade de interações causais que articulam o mundo fisico, da matéria prima até os astros, passando sucessivamente pelos quatro corpos elementares, os mistos, os vivos e os racionais, equivale, neste esquema, a discriminar como incidem os diversos tipos de causalidade: se os princípios operativos de geração e currupção substanciais em cada nível se coordenam causalmente com mudanças acidentais, entendidas real ou nominalmente. Dado que a matéria sozinha é exemplo de passividade, porque por definição está em potência indiferentemente a todas as formas, as causas naturais encontram-se, por outro lado, entre os princípios ativos. Mas desde o ponto de vista da fundamentação, Ockham é bem mais conclusivo com respeito à matéria que às formas substanciais e acidentais: ainda que o caráter de princípio passivo da matéria resulte praticamente deduzido de sua definição de potência para receber indiferentemente todas as formas, maiores reparos são registrados sobre a possibilidade de determinar o papel dos outros dois princípios. Quanto às mudanças acidentais, Ockham argumenta, por exemplo, que se a rarefação e a condensação não são mudanças reais, mas aproximação ou afastamento entre realidades absolutas ou entre partes de realidades absolutas, essas modificacões nominais hão de ser produzidas, por sua vez, por mudanças ou propriedades reais (por exemplo, a condensação pelo frio e a rarefação pelo calor) e similarmente pode-se dar como causas dos movimentos locais dos corpos elementares (a condução até acima ou abaixo) a ditas qualidades primárias (frio, calor, secura e humidade) ${ }^{8}$. Por outro lado, não podemos encontrar uma outra causa dessas qualidades primárias que as próprias formas substanciais (o fogo, a água). Parece igualmente razoável dar ambas conjuntamente (as formas substanciais e acidentais primárias), por causas imediatas ordenadas das qualidades secundárias (a cor, o sabor, etc.). Quanto à substância, se esta pudesse ser despojada de todos os seus acidentes, poderíamos submetê-la ao procedimento usual para saber que algo é causa (sobre o que falaremos mais adiante) e comprovar se tal substância, e não somente seus acidentes, tem poderes causais. Todavia, como as substâncias não subsistem na natureza sem acidentes que as informam, não podemos comprovar estritamente se estas cooperam com seus acidentes, ambos como causas imediatas ordenadas (respectivamente, como principal e subordinada), ou se a substância é puramente causa mediata, porque é substrato do acidente e o 
mantém em seu ser, sendo somente este causa total imediata do efeito que, não obstante, "vemos" produzir a substância:

"(...) si esset hic materia informata forma ignis et alia informata forma aquae, sine omnibus accidentibus hic inde, tunc posset homo experiri certitudinaliter utrum substantia posset generare substantiam sine accidentibus. Et si sic, non poneretur accidentia esse causae partiales respectu illius generationis. Si non, tunc debent poni causae partiales. Sed quia sustantiae non sic manent de facto sine accidentibus, ideo de isto puncto non potest homo certificari, sed remanet quasi conclusio neutra"(OCKHAM, 1984d, q. 9, OTh VII, p. 169, lin. 22 p. 170, lin. 6 y Quaest. in Phys., q. 141, OPhVI, p. 780, lin. 12 - p. 81, lin. 21).

Muitas dessas comprovações são relativas pois não podemos modificar as relações de inerência entre os princípios constitutivos da realidade externa, com o que não podemos levar a cabo uma realização certeira dos experimentos causais. Daí os limites da prova que podemos oferecer para uma proposição causal particular, como "Este calor esquenta" - a qual, é preciso ressaltar, requer comprovação empírica (OCKHAM, 1974, III-II, cap. 4, p. 510, lin. 10-21). Mas se não se pode separar perfeitamente todas as coisas até saber qual ou quais delas efetivamente atuam e quais permanecem, ao contrário, inativas, operando como sujeitos de inerência das que, propriamente atuam, não é essencialmente afetada nossa capacidade de afirmar que estas ações expressam um poder causal desse objeto e, pelo princípio de uniformidade, de todos os de sua classe?

Em favor da interpretação dominante devemos certamente levar em conta que, em alguns textos, Ockham alude às proposições causais particulares como evidentes e que assume certas definições do aristotelismo medieval sobre a necessidade física, como quando afirma, respeitando a educação escolástica, que as causas naturais operam de modo relativamente necessário - ou seja, é necessário que, se posta a causa e cumpridas certas condições, pode dar-se o efeito, etc - e associa a contingência na natureza exclusivamente com a matéria. Mas há que se prestar atenção ao modo em que fundamenta essas afirmações. Com respeito ao tema da contingência das causas, seu argumento é que o contingente em sentido próprio é o que, por si mesmo, é insuficiente para adquirir uma determinação da que carece por mais que se dêem todas as condições sob as quais 
pode fazê-lo, acrescentando que isso é indiferente para operar coisas opostas, pelo que reclama, por definição, algo extrínseco que o determine a operar em um ou outro sentido, já que, do contrário, se determinasse a si próprio a fazê-lo, isto é, se fosse ativo, por não estar mais determinado a um que ao outro contrário, produziria ambos, o que não pode ser, e conclui que, por isso, nada pode ser contingente e ativo: será contingente e passivo ou necessário e ativo (OCKHAM, 1984c, q. 126, p. 735, lin. e 18-25). Esse e muitos outros de seus argumentos em torno de questões de ontologia e causalidade apresentam uma semelhança de família: ao dizer coisas como: "se em cada mudança empírica algo subjaz inalterado, deve haver algo subjacente in rerum natura que não muda"; "se não posso explicar uma mudança da realidade por um rearranjo do preexistente, devo dar por acontecida ali uma verdadeira novidade"; "se, quando aproximo um objeto, dá-se outro, e quando não o aproximava, não, posso dar o primeiro como causa do segundo", Ockham desenvolve uma maneira de filosofar que poderíamos chamar de "fracamente construtiva" e que consiste em analisar o empiricamente manifesto para concluir que há realidades constituintes do empiricamente manifesto (a matéria e a forma) ou operações causais das coisas externas, embora não nos sejam manifestas por si. Este modo de argumentação filosófica é, por assim dizer, oposto e complementar a outro que Ockham também exerce ativamente: o da crítica, especialmente, a da linguagem, que pretende mostrar como as figuras equívocas da linguagem enganam os ignorantes em lógi$\mathrm{ca}$ - os protervos - e os conduzem a postulação, intrinsecamente absurda, de realidades externas universais. A terminante rejeição dessas realidades preludia uma aceitação sensivelmente mais cautelosa, e menos conclusiva, de certos constituintes indiretamente empíricos (e logo, não universais) da realidade externa. A crítica, claramente, vem primeiro e tem um maior grau de evidência; no segundo modo de argumentar, estão incluídas todas as conexões causais. Ockham, em resumo, formula uma teoria que qualificaríamos como "epistemicamente fraca", tanto dos princípios constituintes das entidades físicas, como de sua interação causal.

3. Finalmente, é necessário agora analisar o problema de um ângulo teológico, mas sempre em relação à validação do discurso científico sobre o curso causal da natureza. A interpretação dominante sustenta que o 
princípio de potentia Dei absoluta, tal como o entende Ockham, não afeta os poderes causais enquanto poderes, assim como não afeta, uma vez posta na existência, a ordem das "essências". O argumento central é que, segundo os princípios de Ockham, uma vez criado o mundo "tal como ele é" atualmente, Deus não poderia introduzir uma única modificação nele, nas suas essências ou nos seus poderes causais sem produzir, ipso facto, outro mundo - o que implicaria uma mudança Nele mesmo algo, claramente, inaceitável. A interpretação dominante encarregou-se de esclarecer suficientemente que Ockham não sustenta que Deus "atue" de potentia absoluta: semelhante afirmação, solta, é contraditória, porque todo atuar implica, por si só, uma ordenação - sendo, em todo caso, admissível a proposição "Deus pode atuar de potentia absoluta" (OCKHAM, 1974, cap. 95, pp. 715-729.). Não obstante, esperamos ter demonstrado suficientemente que a própria ontologia que Ockham projetou, com sua ênfase na união contingente de res absolutae, implica que, quoad nos, um conhecimento absolutamente transparente do mundo "tal como é" não é possível. Pretenderemos argumentar que o princípio de onipotência divina (inclusive, devidamente interpretado, ao modo da interpretação dominante) funciona como recurso hiperbólico para colocar essas questões manifestamente na distinção ockhamista entre causas ex natura rei e sine qua non e na definição geral ockhamista de causa.

Agora, que Deus, de facto ou de potentia ordinata, atue sozinho, sem coatuar com nenhuma causa segunda, não é, em si mesmo, impossível ou contraditório: isto é algo reconhecido por Ockham e poderia implicar, ou bem que algumas atuações divinas sem concurso de nenhuma causa segunda estão previstas desde toda eternidade e incluídas no que Deus faz de potentia ordinata -que, como dissemos, equivale, sem mais, a o que fazou bem, que em toda ação Deus atua, de fato como causa total. Ockham diz que, a rigor, nenhuma das duas coisas é, nem contraditória, nem demonstrável. Não seria contraditório que Deus tenha-se ordenado a operar como causa total, dispondo que as criaturas somente sejam causas sine quae non, ou seja, que Deus atue, em toda ação, da mesma forma que atua na causalidade sacramental, na qual se ordenou atuar como uma causa total, só que ante a presença física de algo criado que não atua para nada na produção da graça. Que as criaturas operem significa, pelo contrário, que têm um poder intrínseco (dado, em todo caso, pelo 
Criador, ainda que não seja suficiente para causar sem o concurso Dele, que nesse caso seria parcial). O problema é que a estrutura ontológica própria dos fatos causais, como foi descrita, não permite distinguir, por assim dizer, as leis da graça das leis da natureza. Logo, não pode ser demonstrado que alguma causa segunda é a causa:

"Et ex hoc sequitur quod non potest demonstrari quod aliquis effectus producitur a causa secunda: quia licet semper ad approximationem ignis combustibili sequatur combustio, cum hoc tamen potest stare quod ignis non sit eius causa. Quia Deus potuit ordinasse quod semper ad praesentiam ignis passo approximato ipse solus causaret combustionem, sicut ordinavit cum Ecclesia quod ad prolationem certorum verborum causaretur gratia in anima" (OCKHAM, 1981, p. 72, lin. 21 - p. 73).

Por outro lado, Ockham reconhece que a liberdade da causalidade divina faz com que seja indemonstrável, a partir da essência de Deus, toda ação sua ad extra (algo que todo teólogo ortodoxo concederia). Inversamente, ele chega a afirmar que colocar a ação de Deus é explicativamente desnecessário ou antieconômico - podendo explicar-se tudo suficientemente mediante causas naturais. Por isso ele sustenta, como dizemos, que não se pode demonstrar nem que as causas segundas atuam, nem que Deus atua - seja como causa total, seja como causa parcial. Não podemos entrar aqui na infinidade de dilemas metafísicos que Ockham formula em torno do concurso divino. Todos eles convergem em um mesmo resultado: nenhuma ação causal de fato é, em sentido estrito, demonstrável. A teologia concorda, assim, com a teoria da ciência. O que importa é que a possibilidade lógica da ineficácia das causas segundas está contemplada na definição de causa. Com efeito, à luz de uma causa total no sentido absoluto e não meramente suficiente, como Deus, adverte-se que toda outra causa cumprirá somente em contextos relativos com a definição: "Ser aquele ao qual, ceteris paribus, pode seguir...etc., e sem o qual, ainda dadas as condições, não pode seguir...etc".

Para concluir, retomaremos nossas três argumentações principais:

1. A causalidade e todas as relações entre as criaturas são conceitos que refletem ou significam, não diretamente as realidades absolutas externas, senão nossa própria atividade mental em relação a elas. Isso não significa, 
naturalmente, que tal conceitualização possa dar-se sem certos fatos externos. Qualquer interpretação que se concentre na ideia de "poderes causais" em Ockham enfrenta-se, em nossa opinião, com a forte dialética que Ockham desenvolve e que se poderia reconstruir assim: os "poderes" ou bem são puros conceitos (como tentei argumentar aqui), ou bem são coisas. No caso de que sejam coisas, não poderiam ser senão substâncias ou qualidades, pois no sistema de pensamento de Ockham a própria ideia de "relações internas" não admite outro lugar que as relações trinitárias, as quais ele excluiu explicitamente de seu programa filosófico. No caso de que sejam qualidades (reais, entende-se, o que significa excluir a quarta espécie de qualidade dentro das quatro distinguidas por Aristóteles, isto é, a forma e figura, que para Ockham não são senão nomes conotativos das coisas absolutas), em certa medida realidades absolutas, serão separáveis por Deus, ou seja, contingentes, com o que não se verá a utilidade de postular tais poderes adicionais aos próprios atos causais. No caso de que sejam substâncias, descarta-se claramente que sejam outras substâncias que as singulares e somente existe a possibilidade de que sejam o mesmo que as substâncias singulares. Esta interpretação (Robert, 2002) inscrevese na influente linha de PANACCIO (1991), mas, a nosso ver, implica uma ressubstancialização ou ontologização do conceito de "poder causal" e, então, inevitavelmente, faz desse tão contingente como a substância e/ou a essência da substância com a que é identificado. A noção de poder causal fica a salvo disso, do contrário, se é entendida em termos vazios ou puramente lógicos, como explicaremos no final.

2. A causalidade é a mais complexa e instável das relações quanto a seu conhecimento, não igualável, nesse ponto, à semelhança. A opacidade do mundo, consequência da união contingente entre coisas absolutas no curso comum da natureza, não somente afeta nossa possibilidade de distinguir as respectivas atividades das qualidades vis-à-vis às substâncias, senão também nosso conhecimento dessas últimas que, como Ockham reconhece explicitamente, não é mais que indireto e através das qualidades. E se não apenas nosso conhecimento das operações causais das substâncias, mas também o nosso conhecimento das substâncias chega a ser relativizados por Ockham, não é de estranhar que algo semelhante ocorra com o nosso conhecimento das partes intrínsecas das quais as 
substâncias compõem-se, ou seja, a matéria e a forma, com as quais a interpretação dominante identifica as "essências" das coisas em Ockham.

3. Sustentamos ainda que a doutrina ockhamista do concurso divino não só afirma a contingência das operações causais na medida em que são contingentes as coisas que atuam, mas também na medida em que são contingentes as operações em si mesmas. Esse último apsecto enfraquece a base empírica a partir da qual podemos estabelecer que as coisas têm aquilo que a interpretação dominante chama "poderes causais". Por outro lado, é evidente que, ao reformular os princípios causais em termos de possibilidade, Ockham quer assegurar a universalidade e necessidade de tais princípios. Mas pensamos que o princípio de uniformidade causal da natureza, central nessa reformulação, pode ser interpretado como contendo uma carga de informações muito menor que a que lhe atribui a interpretação dominante. O princípio "Causas da mesma espécie... etc.", que é uma variante do princípio "” que convém a um pode convir a todos", equivale a dizer: "Se, quando pelo menos uma vez, determinada qualidade se verifica em um sujeito, não é contraditório que se verifique uma qualidade similar em qualquer sujeito similar", porque, dados dois indivíduos similares, "não há razão para que a tenha, mais um, que o outro":

"...scito quod quando aliquid convenit uni individuo potest consimile competere alteri individuo eiusdem speciei, accipit istam propositionem universalem 'omnis calor est calefactivus', cum non sit maior ratio quod unus calor sit magis calefactivus quam alius". (OCKHAM, 1974. III-II, cap. 10, OPh I, p. 572)

Assim entendido, o princípio pode ser interpretado como contendo uma regra procedimental para nós, mais que como contendo informação sobre um modo de ser das próprias coisas. Isso significa, aproximadamente como o princípio de economia ou "navalha", que não devemos nos estender na comprovação de mais casos, porque já verificamos uma possibilidade -mais que um poder-. A teoria ockhamista da causalidade é uma tentativa clara de dessubstancializar a ideia de causa e traduzi-la em fatos puros. Atribuir a Ockham a opinião de que os poderes causais são mais que formas substancializadas de falar (metafóricas) sobre fatos puros, seria como retroceder a uma nova e ilícita substancialização. Mesmo Pedro Abelardo não pôde evitar fazer algo semelhante quando depois de 
reduzir a "humanidade" ao fato de ser homem (status hominis), ressubstancializou a natureza humana ao falar de status generales et speciales no Intelecto divino. É de crer que o Venerabilis Inceptor não tenha cometido inconsequência semelhante.

1 A ciência é, para Ockham, "o conhecimento de uma verdade necessária, por meio do conhecimento de duas premissas necessárias e evidentes, dispostas de modo e figura, de tal modo que as duas premissas produzem o conhecimento evidente de uma conclusão que, de outro modo, seria desconhecida". WEBERING, 1953, pp. 9 e 32-41. Sobre a maneira correta de entender, em virtude disso, suas críticas às provas tradicionais da teologia, WEBERING, 1953, pp. ix-xx; BAUDRY, 1962, pp. 84-85; GODDU, 1984, pp. 7-9.

2 OCKHAM, 1985, p. 251, lin. 50: “(...) notandum quod quando Commentator dicit quod 'formae artificiales sunt accidentia in substantiis naturalibus', non intelligit quod formae artificiales sint quaedam accidentia absoluta distincta secundum se tota a substantiis naturalibus et inhaerentia eis, sicut albedo secundum se totam distinguitur a subiecto suo in quo est realiter..."

3 OCKHAM, 1964, I, dist. 31, q. un., p. 401, lin. 1 - p. 402, lin. 4 e 1980, VI, q. 27, p. 688, lin. 60-61 e 69-70. Segui as referências da reconstrução de BERETTA, op. cit., pp. 109-110.

4 Cf. a inclusão dos nomes "causa", "efeito" e similares no predicamento da relação, OCKHAM, 1974, I, c. 52, p. 173, lin. 72 - p. 174 , lin. 80.

5 Além das primeiras quatro questões do prólogo do comentário às Sentenças, veja-se OCKHAM, 1974, III-II, caps. 12, 35 e 37, pp. 525-527, 570 e 575 e 577-579.

6 OCKHAM, 1964, Prol., q. 1, p. 31, lin. 4-6:“(...) notitia intuitiva est talis quod quando aliquae res cognoscuntur quarum una inhaeret alteri vel una distat loco ab altera vel alio modo se habet ad alteram, statim virtute illius notitiae incomplexae illarum rerum scitur si res inhaeret vel non inhaeret, si distat vel non distat, et sic de aliis veritatibus contingentibus (...)".

7 OCKHAM, 1964, q. 2, OTh I, q. 2, p. 87: "Sicut ponatur quod hoc sit primum principium 'omnis herba talis speciei confert febricitanti': ista per nullas propositiones notiores potest syllogizari, sed eius notitia accipitur ex notitia intuitiva forte multorum. Quia enim iste vidit quod post comestionem talis herbae sequebatur sanitas in febricitante, et amovit omnes alias causas sanitatis illius, scivit evidenter quod ista herba fuit causa sanitatis; et tunc habet experimentum de singulari”.

8 Tampouco no caso do movimento local dos corpos vivos é a substância o princípio explicativo suficiente: os animais movem-se imediatamente por qualidades psíquicas ou anímicas como o conhecimento e o apetite e somente mediatamente pela alma (OCKHAM, 1985, II, c. 1, p. 236, lin. 634-640).

doispontos, Curitiba, São Carlos, vol. 7, n. 1, p.113-135, abril, 2010 


\section{Referências bibliográficas}

BAUDRY, L. 1962. "Les rapports de la raison et la foi selon Guillaume d'Occam" em Archives d' Histoire Doctrinale et Littéraire du Moyen Âge, París.

BERETTA, B. 1999, Ad aliquid. La relation chez Guillaume d' Occam, Friburgo.

COURTENAY, W. 1992. "In Search of Nominalism: Two Centuries of Historical Debate”. Em: MAIERU, A. - IMBACH, R., Gli studi di filosofia medievale tra otto e novecento. Contributo a un bilancio storiografico, (orgs.), Roma, pp. 214-233.

GODDU, A., 1984. The Physics of William of Ockham, Leiden - Köln, Brill.

GUILLELMI DE OCKHAM. 1974. Opus Nonaginta Dierum, em: Opera Politica $(=O P)$, Vol. II, 2a ed, Bennett, R. F. - Offler, H. S. - Sikes, J. G. (eds.), Manchester.

MC CORD ADAMS, M. 1979. "Was Ockham a Humean about Efficient Causality?” Franciscan Studies, N.Y., 37, pp. 5-48.

COURTENAY,W. 1984. Covenant and Causality in Medieval Thought, Londres.

OBERMAN, H., 2001. The Harvest of Medieval Theology. Gabriel Biel and Late Medieval Nominalism. Baker Academic.

PANACCIO, C. 1991. Les mots, les concepts et les choses. La sémantique de Guillaume d'Occam et le nominalisme d'aujourd'hui, Montréal - París, Bellarmin - Vrin.

RAYMAN, J. 2005. "Ockham's Theory of Natural Signification", Franciscan Studies, N.Y., 63, pp. 289-323.

ROBERT, A. 2002. "L'explication causale selon Guillaume d'Ockham”, Quaestio, 2, pp. 241-265.

OCKHAM, GUILLELMI DE. 1974. Summa Logicae, em: Opera Philosophica et Theologica ad fidem codicum manuscriptorum edita (= OPh / 
OTh)., 1967-1984, Cura Instituti Franciscani Universitatis S.

Bonaventurae, St. Bonaventure, N.Y.

1985. Expositio in libros Physicorum

Aristotelis, prologus et dist. i-iii, em: OPh. IV,V. Ritcher, G. Leibold (eds.). .1984a, Brevis summa libri

Physicorum, em: OPh.VI, S. Brown (ed.).

.1984b. Summula philosophiae naturalis,

em: OPh.VI, S. Brown (ed.).

1984c. Quaestiones in libros Physicorum

Aristotelis, em: OPh.VI, S. Brown

1964. Scriptum in librum primum

Sententiarum ordinatio, Prologus et dist. prima, em: OTh I, S. Brown, G. Gál (eds.).

1981. Quaestiones in librum secundum

Sententiarum (Reportatio), em: OTh I, G. Gal, R. Wood (eds).

.1984d. Quaestiones in librum quartum

sententiarum (Reportatio), em: OTh VII, R. Wood, G. Gal, R. Green (eds.).

C. Wey, C. S. B. (ed.).

1980. Quodlibeta septem, em: OTh IX, J.

WEBERING, D., 1953, Theory of Demonstration according to William

Ockham, N.Y. - Louvain - Paderborn, The Franciscan Institute. 